\title{
Analisa Optimasi Penggunaan Bandwidth Dengan Failover Dan Load Balance Pada Mikrotik
}

\author{
Wartono $^{1)}$, Bambang Soedijono WA ${ }^{2)}$, Eko Pramono ${ }^{3)}$ \\ Universitas Amikom Yogyakarta \\ Jl. Ring Road Utara, Condong Catur, Sleman, Yogyakarta \\ Email: ${ }^{1}$ wartana4@gmail.com , ${ }^{2}$ bambang.s@ amikom.ac.id, \\ 3eko.p@amikom.ac.id
}

\begin{abstract}
Abstrak
Internet sudah hampir menjadi kebutuhan utama dalam kehidupan sehari-hari. Sehingga karena sangat pentingnya jaringan internet ini maka diperlukan manajemen untuk mengelola jaringann tersebut agar optimal. Pada kasus ini sebuah instansi menggunakan jasa ISP (Internet Servis Provider) Telkom dengan mengambil dua buah koneksi internet masing-masing sebesar 50Mbps. Seperti yang kita ketahui bahwa Telkom menerapkan kebijakan yang dinamakan FUP (Fair Usage Policy), FUP ini bekerja untuk membatasi kecepatan ketika penggunaan data mencapai batas tertentu. FUP ini meliputi Paket 10 Mbpas penggunaan data 300 GB menjadi 7.5 Mbps ketika mencapai 400 GB maka akan menjadi 4.0 Mbps, Paket $20 \mathrm{Mbpas}$ penggunaan data $500 \mathrm{~GB}$ menjadi $15 \mathrm{Mbps}$ ketika mencapai $800 \mathrm{~GB}$ maka akan menjadi $8.0 \mathrm{Mbps}$, Paket $30 \mathrm{Mbpas}$ penggunaan data $700 \mathrm{~GB}$ menjadi 22.5 Mbps ketika mencapai 1200 GB maka akan menjadi 12 Mbps, Paket 40 Mbpas penggunaan data 900 GB menjadi 30 Mbps ketika mencapai 1600 GB maka akan menjadi 16 Mbps, Paket 50 Mbpas penggunaan data 1200 GB menjadi 37.5 Mbps ketika mencapai 2000 GB maka akan menjadi 20 Mbps, Paket 100 Mbpas penggunaan data 2000 GB menjadi 50 Mbps. Pada paket 50Mbps dengan penggunaan data sebesar 2000GB maka kecepatan akan turun menjadi $20 \mathrm{Mbps}$, hal ini tentunya akan membuat ketidaknyamanan menggunakan internet tersebut. Maka dari itu peneliti mencoba menerapkan metode failover dan kemudian metode load balance. Cara kerja metode ini yaitu koneksi utama bekerja dan ketika mencapai penggunaan data sebesar 1200 GB maka akan berpindah ke koneksi cadangan. Ketika koneksi cadangan dalam penggunaan data mencapai 1200GB, maka Load balance akan aktif. Dari sistem tersebut maka akan didapatkan kecepatan yang stabil tanpa adanya fluktuasi yang besar yaitu sebelum failover internet utama ketika FUP pertama kecepatan 37.5Mbps kemudian failover ke koneksi internet backup ketika penggunaan mencapai 1200 GB maka mengaktifkan load balance, sehingga kedua koneksi berjalan dengan kecepatan kurang lebih sebesar 72 Mbps dan menghasilkan koneksi tanpa adanya FUP.
\end{abstract}

Kata Kunci:Mikrotik, Failover, Load balance

\section{PENDAHULUAN}

Saat ini jaringan computer menjadi Kebutuhan akses internet dari hari ke hari semakin meningkat, dikarenakan kemajuan ilmu pengetahuan dan teknologi terutama di bidang Informasi Teknologi (IT) sangat berkembang pesat. Banyak kita jumpai bahwa penggunaan internet terutama di warnet, kantor, sekolahan maupun kampus menggunakan lebih dari satu koneksi dalam berlangganan untuk internet dari Internet Service Provider (ISP) yang sama maupun ISP yang berbeda.

Koneksi internet pada Sekolah Menengah Kejuruan (SMK) Negeri 1 jenar sangat dibutuhkan hal ini dikarenakan sebagai faktor utama dalam menunjang proses kegiatan belajar mengajar dan koneksi data pendidikan instansi SMK ke data pusat pendidikan. Dalam penggunaan internet tersebut sering terkendala dikarenakan pembatasan jumlah pemakaian data dari Telkom yang di sebut Fair Usage Policy (FUP). Koneksi akan down bila pemakaian melebihi kuota yang telah ditentukan oleh pihak Telkom sesuai dengan jenis langganan.

Berdasarkan kebijakan yang diterapkan mengenai Fair Usage Policy (FUP) sangat mempengaruhi kestabilan dalam akses internet, karena membatasi kuota berdasarkan jumlah data yang digunakan. Jasa kecepatan transfer langganan $50 \mathrm{Mbps}$, apabila penggunaan data sampai dengan 2.000 GB data maka kecepatan akan turun $60 \%$ menjadi $20 \mathrm{Mbps}$ hal ini sebagai FUP total.

Berdasarkan kebijakan tersebut maka dapat disimpulkan bahwa berlangganan 50 
Mbps ketika mencapai batas penggunaan data maka hanya akan mendapatkan kecepatan sebesar 20 Mbps saja. Karena hanya tersedia koneksi internet melalui jaringan Fiber Optik (FO). Maka pada penelitian ini mengggunakan 2 (dua) koneksi Gigabit Capable Passive Optical Network (GPON) dengan bandwidth upto $50 \mathrm{Mbps}$ dari ISP yang terdapat di SMK Negeri 1 Jenar Sragen.

Sehingga memperoleh jumlah total bandwidth cukup besar. Dari kendala-kendala tersebut peneliti mencoba membandingkan dan menggabungkan metode Load balancing dan metode Failover untuk mendapatkan koneksi yang stabil dengan menggunakan routerboard Mikrotik.

Metode ini dipakai peneliti karena dirasa sesuai dengan situasi dan kondisi yang terdapat pada SMK Negeri 1 Jenar Sragen yang hanya memiliki 2 buah koneksi internet dari ISP dengan masing-masing memiliki kecepatan upto 50 Mbps. Metode Load balancing merupakan pendistribusian beban trafik atau pengalihan beban trafik berbasiskan jaringan pada dua atau lebih jalur koneksi secara seimbang, agar trafik dapat berjalan optimal, memaksimalkan throughput, memperkecil waktu tanggap.

Sedangkan metode Failover merupakan sebuah sistem untuk dapat berpindah secara manual maupun otomatis jika salah satu sistem mengalami kegagalan sehingga menjadi backup untuk sistem yang mengalami kegagalan (Nikmah \& Prihanto, 2017).

\section{METODE PENELITIAN}

Objek pada penelitian ini adalah optimasi penggunaan bandwidth dengan failover dan load balance pada mikrotik dengan studi kasus pada jaringan internet di SMKN 1 Jenar Sragen. Jaringan internet yang digunakan ialah ISP dari Telkom dengan menggunakan 2 line FO. Penelitian ini dilakukan dengan melakukan eksperimen dan pengamatan pada jaringan di SMKN 1 Jenar Sragen. Sehingga mendapatkan sumber data dan informasi yang dapat digunakan sebagai penelitian.

\section{TINJAUAN PUSTAKA \\ a. Penelitian terdahulu}

Pada penelitian sebelumnya dengan hasil bahwa dengan menggunakan metode failover dengan protocol OSPF yang diterapkan pada jaringan berdampak positif. Hal ini karena akan mengurangi downtime yang akan dirasakan client yang sebelumnya butuh waktu 3 menit untuk bisa menggunakan layanan kembali menjadi kurang dari 5 detik (Bakhtiar Rifai, 2017).

System yang dibangun membutuhkan 2 (Dua) buah aplikasi yaitu GNS3 sebagai simulator jaringan dan Virtualbox sebagai virtualisasi mesin router, dan simulasi routing menggunakan virtual mesin dengan Operating System (OS) Mikrotik pada semua router. Sebaiknya diterapkan langsung pada hardware seperti Routerboard atau router sejenisnya.

Dengan mengimplementasikan teknik load balancing beban traffic pada masingmasing ISP atau gateway, traffic akan menjadi seimbang sehingga pemakaian bandwidth lebih efisien. Teknik load balancing mampu mempercepat koneksi jaringan internet (Pangestu et al., 2018).

Mikrotik dapat mengoptimalkan pembagian bandwidth pada setiap client yang ingin mengakses internet. Penerapkan metode Load balancing PCC (Per Connection

Classifier) menjadi lebih baik, karena telah membagi beban trafik secara seimbang (Futri Utami, Hj. Lindawati, 2017). Sistem yang dirancang dapat membagikan beban secara merata ke beberapa backend server baik dalam keadaan semua server normal atau pun saat terjadi kegagalan pada salah satu backend server (Ilmiah et al., 2017).

Melalui penerapan dua algoritma load balancing, yaitu Max-Min dan Min-Min. Penggunaan kedua algoritma Jika jumlah tugas yang lebih ringan melebihi tugas yang lebih berat, maka Max-Min bekerja lebih baik daripada Min-Min dalam hal pemanfaatan sumber daya dan membuat rentang sebaliknya jika banyak beban yang lebih berat. Hal itu menghasilkan Min-Min dengan kinerja lebih baik daripada Max -Min (P \& Vasudevan, 2015). Pemanfaatan sumber daya maksimal dan kepuasan pengguna dapat ditingkatkan dengan load balancing yang baik (Dhari \& Arif, 2017).

Penggunaan link balancing dapat memanfaatkan besar bandwidth yang ada dan meningkatkan throughput pada saat mengakses data. Throughput pada saat menggunakan metode link balancing pada traffic padat dapat mencapai $8.21 \mathrm{MB} / \mathrm{s}$, sedangkan tidak menggunakan metode link balancing hanya mencapai $1.25 \mathrm{MB} / \mathrm{s} /$.

Begitu juga pada delay, menggunakan link balancing pada saat pengiriman paket hanya 
terjadi delay $1.24 \mathrm{~ms}$ dibandingkan dengan tidak menggunakan metode link balancing yaitu mencapai 8.19 ms. Pada penggunaan Sistem Respon failover pada cisco 7606s sangat baik, hal tersebut dibuktikan bahwa waktu respon failover atau perpindahan ISP pada saat tejadinya fault, adalah rata-rata 2 detik, waktu 2 detik jika di translasikan pada pengiriman paket ICMP, hanya terjadi 1 paket loss (Sukendar, 2017). Pada penelitian selanjutnya untuk meningkatkan rata-rata fault akan menggunakan Mikrotik RB1100AHX4.

Memanfaatkan protocol RSTP (Rapid Spanning Tree Protocol) bisa digunakan untuk failover, pada pengujian dapat dilihat ketika link utama terputus, maka koneksi tetap terhubung melalui link yang lainnya (backup link). Ketika link utama kembali normal maka koneksi akan kembali ke link utama (Nikmah \& Prihanto, 2017).

\section{b. Landasan Teori \\ 1). Optimasi}

Optimasi adalah Suatu disiplin ilmu dalam matematika yang fokus untuk mendapatkan nilai minimum atau maksimum secara sistematis dari suatu fungsi, peluang, maupun pencarian nilai lainnya dalam berbagai kasus. Berdasarkan Kamus Besar Bahasa Indonesia (2016) Optimasi adalah upaya atau cara untuk memperoleh hasil yang terbaik. Sedangkan secara umum optimasi adalah suatu proses untuk mencapai hasil yang ideal atau optimasi (nilai efektif yang dapat dicapai). Optimasi dapat diartikan sebagai suatu bentuk mengoptimalkan sesuatu hal yang sudah ada, ataupun merancang dan membuat sesusatu secara optimal.

\section{2). Bandwidth}

Bandwidth merupakan jumlah data yang dapat ditransmisikan dalam jumlah waktu yang tetap. Untuk perangkat digital, bandwidth biasanya dinyatakan dalam bit per detik (bps) atau byte per detik. Untuk perangkat analog, bandwidth dinyatakan dalam siklus per detik, atau Hertz (Hz). Bandwitdh merupakan faktor terpenting dalam jaringan. Beberapa hal yang menyebabkan bandwidth menjadi bagian penting yang harus diperhatikan adalah:

a) Bandwidth berdampak pada kinerja sebuah jaringan Besarnya saluran atau bandwitd akan berdampak pada kecepatan transmisi. Data dalam jumlah besar akan menempuh saluran yang memiliki bandwidth kecil lebih lama dibandingkan melewati saluran yang memiliki andwidth yang besar. Kecepatan transmisi tersebut sangat dibutuhkan untuk aplikasi real time, seperti video conference.

b) Bandwidth memiliki keterbatasan Setiap medium yang digunakan untuk mentransmisikan data memiliki batas maksimal bandwidth yang dapat dicapai.

c) Kebutuhan bandwidth akan selalu meningkat.

Setiap sebuah jaringan baru dikembangkan dan infrastruktur jaringan yang diperbaharui, aplikasi yang akan digunakan umumnya juga akan mengalami peningkatan dalam hal konsumsi bandwitdh.

\section{3). Failover}

Dalam jurnal penelitiannya (Rifai, Bakhtiar \& Eko Spriyanto, 2017) failover atau redundant link. Banyak system failover yang diterapkan pada network suatu provider internet diantaranya dengan menggunakan teknologi routing dinamis seperti OSPF (Open Shortest Path First) dan BGP (Border Gateway

Protocol). Routing merupakan proses mengirim data dari satu network ke network lain. Dengan dynamic routing maka mekanisme routing dilakukan secara dinamis dengan menentukan jarak terpendek secara cepat dan akurat antara peralatan pengirim dan penerima (Rifai \& Supriyanto, 2017).

Sedangkan menurut (Damar \& Teguh, 2017) dalam jurnal penelitiannya bahwa Failover adalah teknik yang menerapkan beberapa jalur untuk mencapai suatu network tujuan. Namun dalam keadaan normal hanya ada satu link yang digunakan. Link yang lain berfungsi sebagai cadangan dan hanya akan digunakan bila link utama terputus (Darmawan, 2017).

Secara penerapan Teknik Failover adalah suatu teknik jaringan dengan memberikan dua jalur koneksi atau lebih dimana ketika salah satu jalur mati, maka koneksi masih tetap berjalan dengan dialihkan ke jalur lainnya. Teknik failover ini cukup penting ketika kita menginginkan adanya koneksi jaringan internet yang handal dan minimal disconnect dari internet. Teknik ini biasa dilakukan pada perusahaan dimana kegiatannya sangat bergantung pada layanan internet, tapi tidak menutup kemungkinan bahwa perusahaan/ lembaga kecil.

\section{4). Load Balance}

Load balancing adalah teknik untuk mendistribusikan beban trafik pada dua atau 
lebih jalur koneksi secara seimbang, agar trafik dapat berjalan optimal, memaksimalkan throughput, memperkecil waktu tanggap dan menghindari overload pada salah satu jalur koneksi. Load balancing digunakan pada saat sebuah server telah memiliki jumlah user yang telah melebihi maksimal kapasitasnya. Load balancing juga mendistribusikan beban kerja secara merata di dua atau lebih komputer, link jaringan, CPU, hard drive, atau sumber daya lainnya, untuk mendapatkan pemanfaatan sumber daya yang optimal (Bourke, 2001).

Pada umumnya Load balancer digunakan oleh perusahaan layanan yang menginginkan layanannya selalu tersedia setiap saat (high availability). Walaupun secara kenyataan terdapat kendala yang membuat layanan tidak dapat diakses. Misalnya untuk layanan web server. Dengan load balancer, apabila ada 2 server dengan konfigurasi dan tugas yang sama, maka load balancer akan membagi beban ke 2 server tersebut. Dan apabila salah satu server tersebut tidak dapat diakses gangguan, maka server yang lain dapat terus melayani layanan yang diakses oleh user.

\section{5). Mikrotik}

Mikrotik didirikan tahun 1995 bertujuan mengembangkan sistem ISP dengan wireless. Mikrotik saat ini telah mendukung sistem ISP dengan wireless untuk jalur data internet di banyak negara, antara lain Iraq, Kosovo, Sri Lanka, Ghana dan banyak negara lainnya. Berbagai pengembangan telah dilakukan hingga saat ini dengan tersedianya perangkat lunak sistem operasi router versi 2. Menjamin kestabilan, kontrol, dan fleksibilitas pada berbagai media antar muka dan sistem routing dengan menggunakan computer standart sebagai hardware (Moch. Linto Herlambang, 2008).

Perangkat lunak ini mendukung berbagai fitur untuk keperluan dalam jaringan, mulai dari RADIUS modem pool, hingga sirkuit backbone dengan DS3. Mikrotik berlokasi di Riga, ibukota Latvia, dengan 50 orang karyawan. Mikrotik juga menjalankan sebuah ISP kecil, sebagai media percobaan untuk pengembangan Router OS software. Pada penelitian ini menggunakan routerboard jenis RB 1100 AHX4 dengan Router Operating System (ROS) versi 3.64.3. RB 1100 AHX4 memiliki spesifikasi cukup mumpuni untuk melakukan load balancing dan failover secara stabil. Spesifikasi RB tersebut adalah Dengan Architecture ARM, CPU Alpine AL21400
1.4GHz Quad Core, Main Storage/NAND 128MB, RAM 1GB, LAN Ports ,13 Gigabi Router, OS License Level6.

\section{HASIL DAN PEMBAHASAN a. Pengolahan Data}

Pada tahapan ini peneliti mengolah data default dan data yang dimanajemen. Data default berupa data pengaturan pokok yang terdapat di mikrotik RB 1100 AHX4 tanpa menambahkan metode failover ataupun load balance sehingga trafik yang keluar dari mikrotik merupakan trafik murni tanpa ada penambahan metode apapun. Dalam pengolahan data yang dimanajemen, peneliti menerapkan dua metode yang digunakan untuk mengoptimalkan bandwidth serta perangkat yang ada pada SMK Negeri 1 Jenar Sragen.

Pertama peneliti menggunakan failover sebagai switching antar modem, cara kerjanya bisa dilihat pada gambar 1 .

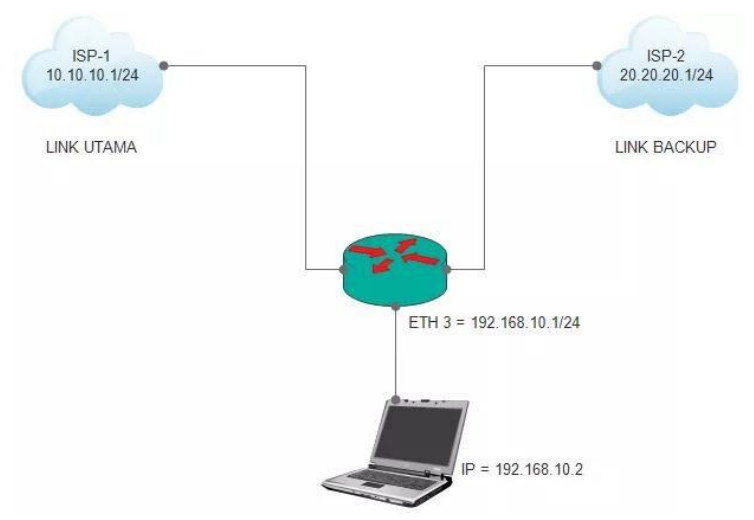

Gambar 1. Failover dan Load balance

Dari gambar 1 dapat dijelaskan, bahwa terdapat dua buah koneksi internet yaitu link utama dan link backup. Dalam penelitian ini apabila link utama mencapai $1.200 \mathrm{~GB}$ saat penggunaan data maka akan otomatis berpindah ke link backup. Kemudian apabila link backup mencapai 1.200 GB dalam penggunaan datanya maka kedua link tersebut akan bekerja bersama-sama menjadi load balance.

Untuk mengukur penggunaan bandwidth baik pada link utama atau link backup peneliti menggunakan script yang ditanam dalam mikrotik, yang ditunjukkan pada gambar 2 . 


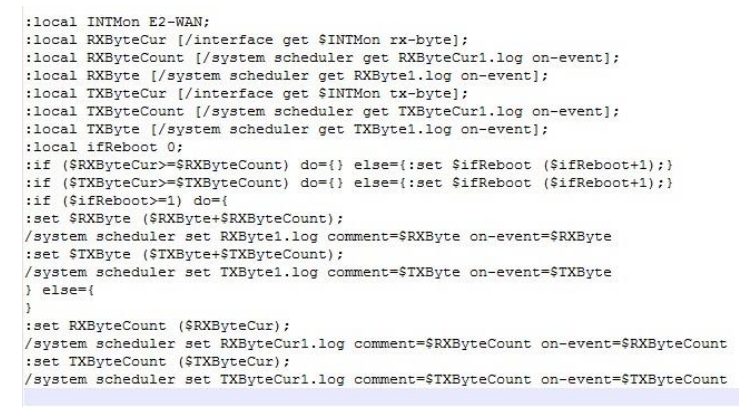

Gambar 2. Script Monitor Link Utama

Gambar 2 merupakan script yang digunakan untuk mengetahui jumlah penggunaan data yang terdapat pada link utama. Cara bekerja, script mendeteksi setiap paket data yang keluar dari interface yang berasal dari link utama, jika interface output lebih dari satu maka akan dikalkulasikan jumlah penggunaan data yang berasal dari link utama. Sehingga penggunaan data akan ditampilkan pada Log secara realtime. Script Monitor link backup di tunjukkan pada gambar 3.

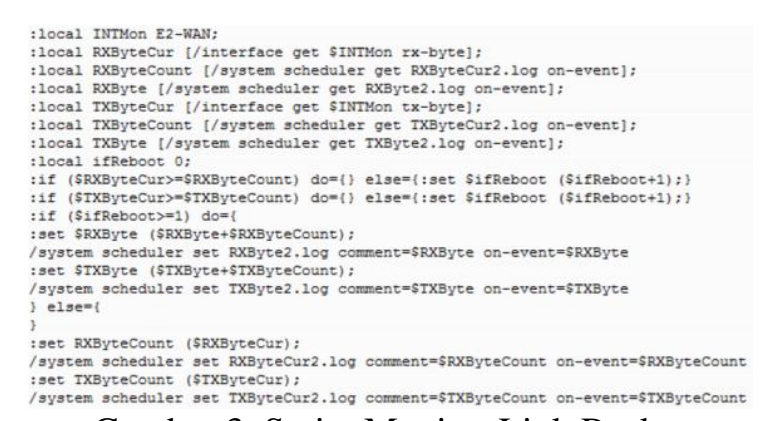

Gambar 3. Script Monitor Link Backup

Gambar 3 merupakan script yang digunakann untuk mengetahui jumlah penggunaan data yang terdapat pada link Backup. Cara bekerjanya adalah script mendeteksi setiap paket data yang keluar dari interface yang berasal dari link Backup, jika interface output lebih dari satu maka akan dikalkulasikan jumlah penggunaan data yang berasal dari link utama, shingga penggunaan data akan ditampilkan pada Log secara realtime.

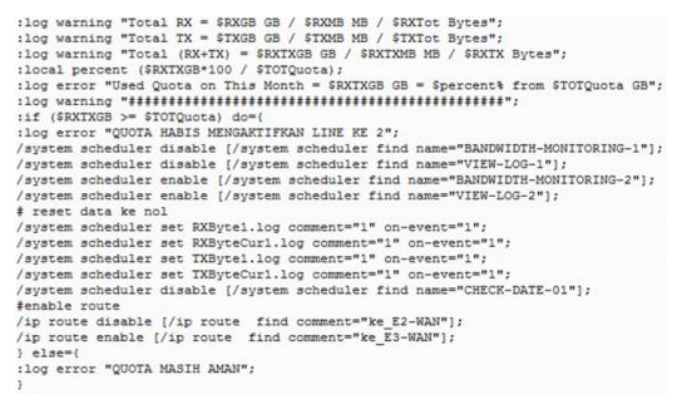

Gambar 4. Script Fail Over
Tampilan script gambar 4 digunakan untuk system Failover, system ini digunakan untuk switching secara otomatis. Cara kerjanya adalah ketika link pertama dalam penggunaan data dan tampilan Log sudah menunjukkan 100\% yang dibatasi dengan limit 1.200 GB, maka system akan secara otomatis memindah koneksi sumber internet yang awalnya berasal dari link utama menjadi link backup.

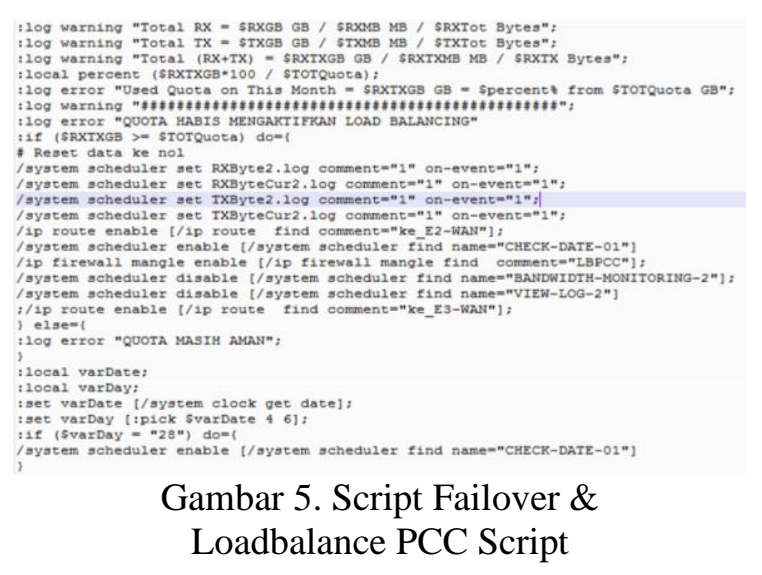

Pada gambar 5 merupakan script yang digunakan sebagai system failover sekaligus sebagai system loadbalance, cara kerjanya hampir sama yakni ketika link backup dalam penggunaan data dan tampilan Log sudah menunjukkan $100 \%$ yang dibatasi dengan limit 1200 GB, maka system akan secara otomatis memindah koneksi sumber internet yang awalnya berasal dari link backup menjadi link utama dan link backup, hal ini bertujuan untuk mendapatkan jumlah koneksi data yang stabil sehingga tidak terjadi fluktuasi koneksi.

\section{b. Hasil}

Pada tahapan ini hasil dari pengolahan data pada router yang menggunakan management bandwidth dapat diambil dari data $\log$ mikrotik, data log bekerja berdasarkan script yang dibuat. Script yang dibuat dan ditanam di mikrotik dalam penelitian ini berupa script monitoring bandwidth, script penjadwalan failover dan script load balance. Script monitoring ini bertugas melakukan monitoring pada setiap interface yang digunakan pada mikrotik, hasil monitoring dikalkulasi dan setiap 10 detik ditampilkan pada Log mikrotik. Script failover bekerja untuk mendeteksi perpindahan koneksi, ketika sebuah koneksi mengalami batas limit penggunaan data yang sudah ditetapkan maka akan melakukan perindahan secara otomatis. Script load balance, pada script ini bekerja untuk mendeteksi ketika kedua koneksi 
mencapai batas limit tertentu maka akan menggabungkan kedua koneksi tersebut agar bekerja bersama-sama sehingga menghasilkan koneksi yang stabil tanpa ada fluktuasi yang terlalu tinggi.

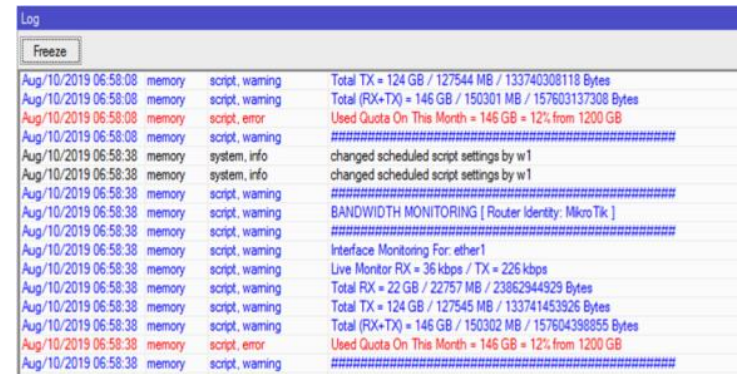

Gambar 6. Tampilan log Link utama \& Backup

Gambar 6 merupakan tampilan log mikrotik yang didapat berdasarkan script yang ditanam baik untuk link utama maupun link backup. Dari gambar menunjukkan total penggunaan data yang dibatasi pada limit 1.200 GB, harapannya ketika link utama sudah mencapai 1.200 GB maka akan otomatis pindah ke link backup sehinngga tidak akan terjadi Fup (Fair Usage Policy) Pada link utama. Tampilan diatas juga berlaku untuk link backup dengan cara kerja yang sama dengan titik limit penggunaan bandwidth sebesar 1.200 GB.

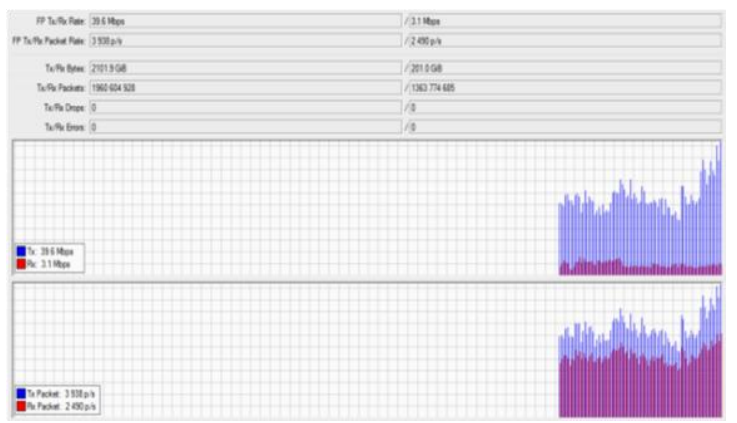

Gambar 7. Grafik Koneksi Link Utama

Pada gambar 7 diatas menunjukkan keadaan koneksi link utama dengan trafik sebesar 39.6 Mbps, setelah link utama mengalami FUP pertama dengan batas penggunaan data sebesar $1200 \mathrm{~GB}$.

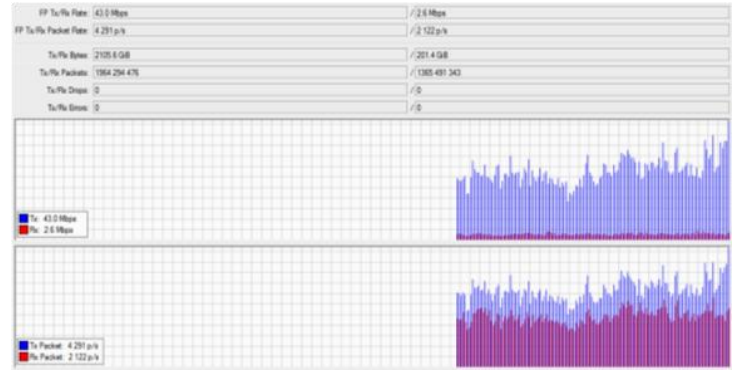

Gambar 8. Grafik Koneksi Link Backup

Pada gambar 8 diatas menunjukkan keadaan koneksi setelah fileover dari link utama ke link backup dengan trafik sebesar 43.06 Mbps, sebelum link backup mengalami FUP pertama dengan batas penggunaan data sebesar 1200 GB.

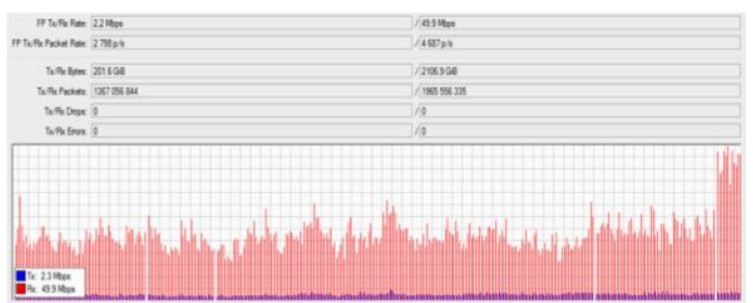

Gambar 9. Grafik Koneksi Load Balance

Pada gambar 9 diatas menunjukkan keadaan koneksi setelah fileover dari link backup ke load balance, dari gambar ini menunjukkan koneksi setelah link backup mengalami FUP dan mengaktifkan lodbalance sehingga kedua link menyatu dan menghasilkan koneksi yang tetap stabil.

\section{KESIMPULAN DAN SARAN a. Kesimpulan}

Berdasarkan penelitian yang dilakukan peneliti, dapat disimpulkan. Bahwa untuk dua koneksi internet Telkom yang masing-masing konesksi memiliki kecepatan sebesar 50Mbps, dapat menggunakan metode ini. Untuk mendapatkan koneksi yang tetap stabil.

Hal ini digunakan untuk menghindari penurunan speed yang cukup drastis berdasarkan kebijakan Telkom yang disebut sebagai FUP. Seperti yang kita ketahui bahwa untuk koneksi indihome sebesar 50Mbps ketika mengalami FUP pertama maka kecepatan akan turun menjadi 37,5 Mbps, dan ketika mengalami FUP kedua atau FUP total maka kecepatan akan menurun hingga menjadi 20 Mbps.

FUP ini bekerja berdasarkan penggunaan data, untuk FUP pertama akan berjalan ketika 
kita sudah memakai data sebesar 1.200 GB dan FUP total akan berjalan ketika kit menggunakan data sebesar 2.000 GB. Maka dalam penelitian ini peneliti menerapkan pembatasan penggunaan data sebesar maksimal $1.200 \mathrm{~GB}$.

Hal ini bertujuan sebelum koneksi utama mengalami FUP total maka system akan memindah koneksi secara otomatis ke Koneksi cadangan dan setelah koneksi cadangan mengalami FUP pertama maka koneksi akan dijadikan satu. Sehinggan dengan metode ini diharapkan kita tetap mendapatkan koneksi rata-rata sebesar 50 Mbps tanpa mengalami FUP total.

\section{b. Saran}

Pada penelitian ini peneliti menggunakan 2 koneksi yang masing-masing koneksi memiliki kecepatan sebesar 50 Mbs, untuk kedepannya bisa menggunakan kecepatan yg lebih besar. Selain itu peneliti menggunakan 1 ISP yaitu Telkom, mungkin metode ini juga bisa diterapkan pada ISP yang berbeda dengan modifikasi script yang sudah ada.

\section{REFERENSI}

Bakhtiar Rifai, E. S. (2017). Management System Failover Dengan Routing Dinamis Open Shortest Path First Dan. Jurnal Ilmu Pengetahuan Dan Teknologi Komputer, 3(1), 39-46. Bourke, T. (2001). Server Load balancing. 101 Morris Street, Sebastopol, CA 95472.: O'Reilly \& Associates, Inc.

Darmawan, T. I. (2017). Analisa Link Balancing dan Failover 2 Provider Menggunakan Border Gateway Protocol (BGP ) Pada Router Cisco 7606s. Jurnal Nasional Teknologi Dan Sistem Informasi, 03, 326-333.

Dhari, A., \& Arif, K. I. (2017). An Efficient Load Balancing Scheme for Cloud Computing, 10(March). https://doi.org/10.17485/ijst/2017/v10i11 $/ 110107$

Futri Utami, Hj. Lindawati, S. (2017). Optimalisasi Load Balancing Dua Isp Untuk Manajemen Bandwidth Berbasis Mikrotik.

Prosiding Seminar Nasional Multi Disiplin Ilmu \& Call For Paper Unisbank, 3(3), 7582. Retrieved from https://www.neliti.com/id/publications/17
31 84/optimalisasi-load-balancing-duaispuntuk-manajemen-bandwidthberbasismikrotik

Ilmiah, P., Dani, R., Informatika, P. S., Komunikasi, F., Informatika, D. A. N., \& Surakarta, U. M. (2017). Perancangan Dan Pengujian Load Balancing Dan Failover.

Moch. Linto Herlambang, A. C. L. (2008). Panduan Lengkap Menguasai Router Masa Depan Menggunakan MikroTik RouterOS TM. Yogyakarta: Penerbit ANDI Yogyakarta.

Nikmah, K., \& Prihanto, A. (2017). Failover Dengan Menggunakan Metode Bonding Pada Mikrotik, 8(1), 1-9.

P, G. G. P., \& Vasudevan, S. K. (2015). An indepth analysis and study of Load balancing techniques in the cloud computing environment . Procedia Procedia Computer Science, 50, 427432.

https://doi.org/10.1016/j.procs.2015.04.009 Pangestu, Y., Setiyadi, D., Khasanah, F. N.,

Serpong, S., Boulevard, J., Serpong, G., \&

Dua, K. (2018). Metode Per Connection Classifier Untuk Implementasi Load Balancing Jaringan Internet, 6(1), 1-7.

Rifai, B., \& Supriyanto, E. (2017). Management System Failover Dengan Routing Dinamis Open Shortest Path First Dan Border Gateway Protocol, 3(1), 39-46.

Sukendar, T. (2017). Menjaga konektifitas Internet Agar Selalu Up Dengan Metode Fail Over Berbasis Mikrotik Pada SMA Darusallam Jakarta, III(2), 48-52. 